DOI: 10.11606/issn.2318-8855.v6i6p283-303

\title{
O sagrado, o profano e os seus diferentes tempos convergentes: uma fotografia "futebolística" de Peter Robinson (Liverpool, Inglaterra, 1971)
}

Celso Vieira Jr.*

Resumo: Tomando a fotografia como um documento histórico, analisamos os quatro elementos dominantes de uma imagem obtida em Goodison Park, estádio do Everton FC, em 1971: um relógio, um estádio, uma igreja e uma multidão. A análise dos elementos, tomada individualmente ou em suas relações, nos permite compreender diferentes tempos e usos da história baseados em ideias sobre modernismo, pós-modernismo, usos e costumes do presente e do passado, arquitetura, religião e sociedade.

Palavras-Chave: Tempo; Relógio; Futebol; Igreja; Fotografia; Liverpool.

\section{A fotografia como fonte histórica}

Este artigo analisa uma fotografia. Não é o objetivo aqui discutir a importância e o uso da imagem como fonte histórica e sim as possibilidades de análise de tempos históricos por meio deste instrumento. Segundo Le Goff (1979, p. 59):

o pintor reduz o seu quadro ou seu fresco à unidade temporal de um momento isolado, agarra-se ao instantâneo (que por fim será fixado pela fotografia) enquanto que o tempo, o tempo romanesco, poderíamos dizer, está restituído nos seus ciclos murais [...]. Triunfa o retrato, que já não é a imagem abstrata de uma personagem representada por símbolos [...] mas que mostra o indivíduo inserido no tempo, no concreto espacial e temporal.

Ou seja, a partir do instantâneo, tentamos obter a percepção objetiva de uma realidade que, trasladada no tempo, nos permita fazer uma análise a partir de elementos sobre o

\footnotetext{
* Graduado em Administração de Empresas pela Universidade Federal de Uberlândia. Graduando em História pela Universidade de São Paulo. Contato: celso.vieirajr@yahoo.com.br
} 
Celso Vieira Jr.

passado (e o presente). Interessante notar que a passagem do tempo acaba por constituir o próprio documento. A decisão do fotógrafo, assim como o era para o artista na Renascença, baseia-se numa intuição sobre algo relevante a ele naquele momento, e que Aumont chamará de "instante pregnante" (AUMONT, 2004, p. 51). Interessa-nos aqui a abordagem de Aumont pois, embora tenha baseado sua análise na pintura e no cinema, há muitos elementos que se permitem transportar para a fotografia, com vantagem para a esta última na captura do "instante pregnante" ideal, no sentido da capacidade tecnológica de capturar o fugidio (AUMONT, 2004, p. 53); algo que o pintor também deseja, porém enfrenta a incapacidade de congelar o tempo para o registro de seu instante. Servimo-nos da análise cinematográfica para a imagem em questão por ter sido obtida por um fotojornalista cuja formação e ambição voltou-se, em meio a linguagens visuais, também ao cinema.

Em uma fotografia, uma boa parte daquilo considerado "natural" ou "corriqueiro" ganha valor ao ser confrontado por um tempo diverso, seja este um tempo cronológico ou não. Este é um dos elementos no qual reside o valor historiográfico de uma fotografia. No que nos concerne neste artigo, encontramos na fotografia que lhe é central três tempos maiores, condensados simultânea e dinamicamente na imagem: o tempo das coisas passadas, representado por elementos que foram fotografados (construções, natureza, pessoas) e registrados simultaneamente; registrados, portanto, em um tempo presente (que nos é "passado"), situado no momento da ação do fotógrafo; e o futuro deste presente "passado", representado pela transcendência do registro, pela reinvenção da fotografia por toda pessoa que se põe a observá-la num momento que, evidentemente, só pode ser posterior ao registro. Bem se vê, portanto, que esses três tempos maiores se decompõem em muitos outros, ou, de acordo com Aumont, encontram-se pluralmente "pregnantes" de sentido.

\section{O fotógrafo e a fotografia}

Peter Robinson, fotógrafo britânico, formou-se na Royal College of Art. Sua primeira intenção era trabalhar como diretor de cinema. Começou sua carreira em 1965 fotografando para documentários. Robinson tornou-se um fotojornalista do futebol por acaso, após 
O sagrado, o profano e os seus diferentes tempos convergentes: uma fotografia "futebolística" de Peter Robinson (Liverpool, Inglaterra, 1971)

receber uma oferta de trabalho freelancer para cobrir a final do Campeonato Europeu de 1968 entre Manchester United e Benfica. A partir deste trabalho surgiram outros que culminaram numa carreira com mais de 35 anos e nove Copas do Mundo fotografadas. A característica que percorre a obra de Robinson são os instantâneos sobre os entornos do futebol; raras são suas fotos sugerindo movimento, e boa parte delas são sobre o cotidiano dos clubes, torcidas e estádios. Mesmo suas fotos sobre o jogo em si apresentam um carácter incomum: não foram feitas para a capa do jornal do dia seguinte, e sim como registros que sugerem explicações sociais, políticas e, em alguns casos, emotivas (BEAZLEY, 2006, p. 11).

A fotografia aqui em foco é uma imagem da multidão espremida no corner end do Goodison Park, estádio do Everton FC, sediado em Liverpool, com a igreja de St. Luke the Evangelist ao centro e ao fundo. À esquerda, quase em primeiro plano, um relógio. Temos aqui quatro elementos fundamentais: a multidão, o estádio, a igreja e o relógio. Em uma primeira aproximação, pode-se dizer que a principal intenção de Robinson era enquadrar simultaneamente todos estes elementos como forma de registrar o "momento pregnante" (AUMONT, 2004, p. 81), ou seja, carregado de sentidos a partir da composição de elementos temporais diversos. A foto foi feita no ano de 1971. O Everton havia sido campeão da Liga na temporada anterior e disputava neste ano a Copa Europeia dos Campeões da UEFA. Não é possível perceber isso pela imagem, mas segundo o site oficial do Everton, havia uma reforma ocorrendo, mais especificamente no Goodison Road Stand, setor à esquerda do relógio na imagem e que divisa com a Gwladys Street End, setor que ocupa o centro e a parte direita da foto e cuja estrutura é visível no canto superior direito.

A relação entre Goodison Park e a igreja de St. Luke the Evangelist é famosa na GrãBretanha. Robinson, fotojornalista de futebol e frequentador de estádios por oficio desde 1968 pelo menos, talvez estimulado pela ideia de mudanças que a reforma da Goodison Road Stand poderia trazer, pode ter entendido a importância em registrar um cenário que poderia vir a deixar de existir. No entanto, devemos lembrar que Robinson deliberadamente propõe a interpretação de sua própria decisão a quem vê a imagem. A Robinson interessam os 
Celso Vieira Jr.

cenários e composições para além do jogo em si; detalhes marginais, como por exemplo a capacidade que o futebol tem de atrair a multidão e como este a afeta. Portanto, na linguagem de Robinson, retratar a vizinhança entre igreja e estádio é mais significativo do que informar qual o adversário do dono da casa em mais um jogo corriqueiro da liga.

O que se sabe sobre as circunstâncias da partida na imagem é que, pelo relógio, pela luz do dia e pelo evento, são três horas e seis minutos de uma tarde de sábado em Liverpool. O Everton, por muitos anos jogou todas as suas partidas vespertinas aos sábados. Apenas durante a greve dos eletricitários ingleses os jogos foram disputados à tarde, como aponta Hornby: “no entanto esta permanece sendo a única vez na qual uma partida do time principal tenha acontecido em Highbury em uma tarde de meio de semana durante meus tempos de torcedor assíduo do Arsenal: fevereiro [de 1972] foi a época da greve dos trabalhadores de mineração e energia [no Reino Unido] "“ (HORNBY, 1992, p. 58). E a alteração de horário que se aplicou ao Arsenal aplicou-se também ao Everton em $1972^{2}$. Provavelmente, a primeira partida de futebol oficial disputada aos domingos na Inglaterra ocorreu apenas em 20 de janeiro de 1974, entre Millwall e Fulham, válida pela segunda divisão (THE GUARDIAN, 2010). O Everton só viria a disputar uma partida em um domingo no dia 26 de maio de 1985, quando perdeu para o Coventry por 4 a 1. A primeira partida em casa, aos domingos, viria no ano seguinte: vitória por 1 a 0 sobre o Exeter City, válida pela FA Cup (EVERTON RESULTS,2018). Partidas de meio de semana surgiram quase que concomitantemente com o futebol organizado na Inglaterra e, em 1878, a iluminação artificial foi introduzida para que tais partidas fossem disputadas à noite. A decisão pela noite deu-se como forma de evitar conflitos com a jornada de trabalho de seus potenciais espectadores.

1 No original: "But it remains the only first-team game that has taken place at Highbury on a midweek afternoon during my Arsenal time: February was the time of the power's workers' strike"

2 "Strike" no caso refere-se a greve dos mineiros de Saltley, Birmingham. Nos anos 1970 a usinas termelétricas movidas a carvão ainda eram significativas na Grã-Bretanha. No entanto, esta fonte de energia foi sendo reduzida a partir desta greve e hoje em dia é apenas de uso pontual (BBC, 2013). 


\section{dossiê}

O sagrado, o profano e os seus diferentes tempos convergentes: uma fotografia "futebolística" de Peter Robinson (Liverpool, Inglaterra, 1971)

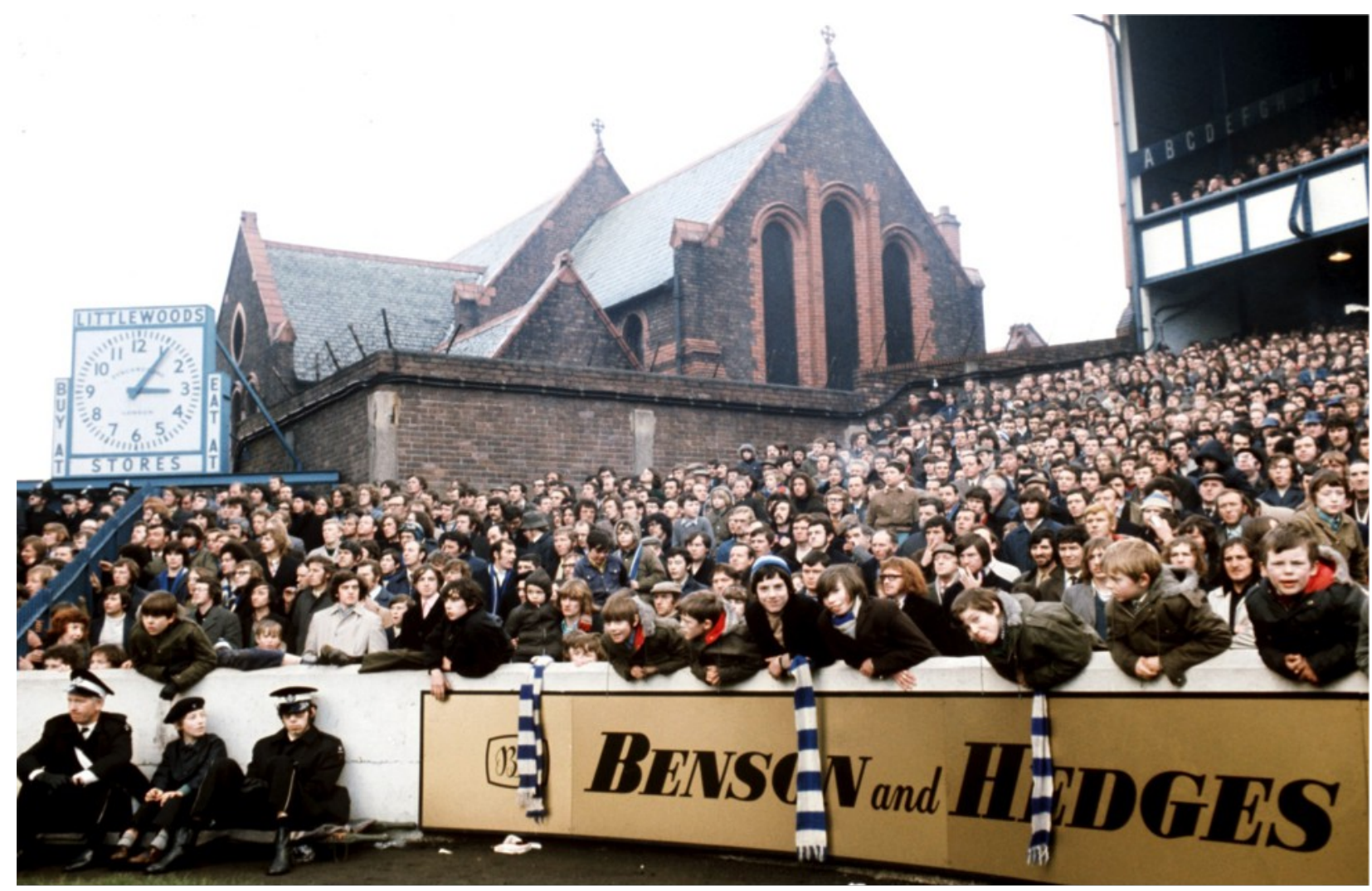

Imagem 1: O corner end do Goodison Park com igreja de São Lucas Evangelista ao fundo, situada na esquina formada entre a Goodison Road e Rua Gladys (The Church of St Luke the Evangelist in the corner of the ground, with the Gladwys Street End to the right). Peter Robinson, 1971 Fonte: PA Images.

Uma vez enquadrados igreja e estádio, temos uma espécie de oposição entre ambos, divididos por um muro encimado por arame farpado e mediados pelo relógio à esquerda da imagem. A igreja está de costas ao estádio; o que se vê na imagem é o fundo da igreja cuja fachada principal está voltada para Goodison Road. O estádio e a igreja são de fato vizinhos na mesma rua. Neste cenário, vemos uma multidão que está voltada em sua maioria para o que acontece no gramado. A imagem também nos traz uma sensação de claustrofobia. Centenas de pessoas se espremem de pé num espaço exíguo.

Uma cerca de arame farpado ergue-se sobre o muro do estádio, como forma de contenção (PALIN apud BEAZLEY,2003, p. 6), sinalizando uma fronteira de hostilidade entre ambos os espaços. No entanto, esta é apenas uma impressão causada pela imagem. A relação entre clube e igreja não é de oposição, e sim de convivência. Os horários entre os 
Celso Vieira Jr.

jogos do Everton e da igreja raramente coincidem, porém quando isto ocorreu, a preferência de horário foi dada a igreja. Em 2002, por exemplo, a The Football Association (The FA, Federação Inglesa de Futebol), definiu a partida entre Everton e Crewe United para 17 de fevereiro, às 13 horas, para transmissão via BBC. O reverendo Harry Ross, então responsável pela St. Luke Evangelist, fez um requerimento ao Everton de alteração de horário da partida, pedindo sua prorrogação em pelo menos 30 minutos. O Everton, por sua vez, acatou o pedido e o encaminhou à FA, que alterou o horário de início da partida, conforme reportagem publicada pela BBC, naquele ano. A igreja também tem uma atividade chamada "Tea for Fans", na qual oferece chá em sua igreja aos torcedores que chegam para assistir às partidas. Do mesmo modo, também oferece seus bancos e jardins para descanso dos torcedores nos dias de jogos. A Everton Football Club Heritage Society, uma associação sem fins lucrativos fundada em 2008 e mantida por torcedores do Everton, realiza no segundo andar da igreja uma recepção a torcedores todas as vezes que o Everton joga em Goodison Park (EFC HERITAGE SOCIETY,2018). Nestes eventos os voluntários organizam uma exposição de memorabilia e sempre que possível contam com um ex-jogador da equipe que se disponibiliza a conversar e tirar fotos com os torcedores. Tais ações demonstram o forte vínculo entre a igreja e o clube.

\section{O relógio}

O relógio ocupa o que seria uma faixa central horizontal da imagem, porém fora do centro; tampouco parece ser o alvo preferencial do fotógrafo; no entanto ele não é menos importante. Pelo contrário: ele é quase que onipresente. Ainda que o relógio se apresente de certa forma periférico, podemos perceber a formação de uma convergência para o relógio pelas linhas traçadas pelo muro, pela igreja e pelo muro estampado com a publicidade da marca de cigarros Benson \& Hedges que divide o público do gramado. Ou seja, temos uma composição imagética que aponta uma preponderância ao relógio mesmo quando fora do centro da imagem. O relógio em questão é um dos dois "Littlewoods Clock", nome pelo qual ficaram famosos os relógios de Goodison Park por conta da empresa de departamentos que 
O sagrado, o profano e os seus diferentes tempos convergentes: uma fotografia "futebolística" de Peter Robinson (Liverpool, Inglaterra, 1971)

estampa sua marca no entorno do relógio. Tais relógios tornaram-se icônicos de tal forma que dele já chegaram a ser vendidas réplicas em miniaturas, dado seu suposto valor estético, histórico e nostálgico (TOFFEEART,2018). Estes relógios, confeccionados pela marca Synchronome, de Londres, só foram retirados do estádio em 1985, quando um novo placar eletrônico foi instalado em Goodison Park. Atualmente há dois telões eletrônicos posicionados onde anteriormente ficavam os "Littlewoods Clocks".

O relógio já vinha sendo o ordenador dominante da sociedade ocidental desde pelo menos a Revolução Industrial (THOMPSON, 1998, p. 279), e continuava a sê-lo na sociedade aqui representada. A partir da Inglaterra fabril do século XVIII, forja-se a primeira classe operária a ser totalmente regulada pelo relógio, tanto na fábrica quanto fora dela. Do lado de fora do muro (porém bem próximo a ele), emerge na virada do século XIX para o XX uma das principais opções de lazer para as massas: o futebol.

As classes ociosas começaram a descobrir o "problema" (sobre o qual se discute muito hoje em dia) do lazer das massas. Depois de concluir o seu trabalho, uma considerável quantidade de trabalhadores manuais ficava com várias horas do dia a serem gastas como se lhe aprouvesse. (THOMPSON, 1998, p. 298)

E no caso do futebol, o relógio não só é ordenador, como também parte integrante do jogo, todo ele cronometrado. Além do mais, o relógio condiciona seus ritmos: a forma como uma partida se desenrola em seus primeiros minutos é diferente do ritmo como se desenvolve em seus momentos finais, por exemplo. É como se os jogadores possuíssem um acordo sobre qual intensidade aplicar à partida de acordo com o momento de jogo (PRADO, 1989).

O relógio não só é fundamento mediador da sociedade industrial, regulador de tempos sagrados e profanos, como também possui uma própria essência profana. O relógio tem valor econômico expresso pela sua utilidade, mas também pelo trabalho de artesanato nele empregado (os cronógrafos de luxo, por exemplo), e de distinção social. Ao relógio da foto, por exemplo, além das suas características intrínsecas de valor econômico e uso social 
Celso Vieira Jr.

corriqueiro, atribui-se também valor histórico e nostálgico por conta de sua presença em um dos estádios mais emblemáticos da Grã-Bretanha. Ao serem substituídos por outros mais modernos, tais relógios foram descartados e posteriormente resgatados. Um deles foi conservado em casa por um torcedor do Everton (LIVERPOOL ECHO,2015) contratado para retirá-los de Goodison Park em 1985. Como naturalmente muita gente se volta aos relógios por vários momentos durante o dia, entende-se com facilidade a existência, no entorno do relógio da imagem, de uma publicidade da loja de departamentos Littlewoods, mais visível e destacada que a própria marca da manufatura do relógio.

Outro ponto a se destacar na fotografia é a ausência do relógio na igreja. Conforme Thompson (1998, p. 274): “Do século XIV em diante, construíram-se relógios de igreja e relógios públicos nas cidades e nas grandes cidades-mercados. A maioria das paróquias inglesas devia possuir relógios de igreja no final do século XVI". A construção da St. Luke Evangelist Church é atribuída ao arquiteto James Francis Doyle, famoso em Liverpool pelas construções dos prédios de escritórios da companhia White Star and Royal Insurance, a mesma que operava a linha de navegação do Titanic ${ }^{3}$. Havia no projeto de um pináculo e de uma torre no plano original que acabou não sendo executado por motivos econômicos (EFC HERITAGE SOCIETY, 2018). Não há informações sobre a provável existência de um relógio nesta hipotética torre, embora tal artefato seja comuns neste tipo de construção. A St. Peter's Cathedral, a sede do bispado anglicano de Londres, por exemplo, apresenta um, assim como a igreja de St. Luke, conhecida como "Bombed Out Church", por conta dos danos causados pelos bombardeios aéreos sofridos por Liverpool durante a Segunda Guerra Mundial. A igreja permanece de pé como uma ruína conservada e é utilizada hoje em dia como sede de eventos. É possível ver a presença do relógio em sua coluna principal. Portanto, a ausência do relógio na St. Luke the Evangelist compõe uma oposição de tempos: a composição da imagem nos induz a entender a mudança do regime do tempo cronológico do sagrado para o profano (LE GOFF, 1989, p.53). A igreja agora detém o tempo ritual apenas, prescindindo do relógio. E, um tanto quanto paradoxalmente, a audiência poderia prescindir do relógio uma vez que nos 3 Sítio eletrônico da St. Luke Evangelist Church 
O sagrado, o profano e os seus diferentes tempos convergentes: uma fotografia "futebolística" de Peter Robinson (Liverpool, Inglaterra, 1971)

anos 1960/70 os relógios de pulso já eram mundialmente popularizados. A presença do relógio no corner end na imagem reforça a necessidade de tornar público o controle do tempo do jogo de futebol. Não é coincidência que, como afirmamos anteriormente, um dos dois painéis eletrônicos em uso hoje pelo Everton em Goodison Park ocupe o mesmo espaço (o outro situa-se no corner end oposto, entre a Bullens Stand e Park End).

\section{O estádio}

O estádio de Goodison Park foi erguido em 1892 para ser a nova casa do Everton FC, que deixou Anfield Road devido a uma desavença política e financeira com John Houlding. Ainda que fosse um dos homens fundamentais para a criação e sustentação do Everton, Houlding era acima de tudo um importante empresário de Liverpool, e como tal colocou diversas exigências financeiras para o clube que acabaram causando atrito entre ele e os outros membros do comitê diretivo do Everton (KENNEDY, 2017, p. 12). O Everton acabou despejado de Anfield Road, e o Liverpool, que viria a ser fundado no mesmo ano de $1892 \mathrm{sob}$ a liderança de Houlding, instalou-se sobre as bases deixadas pelo Everton. Ambos estádios se encontram separados por pouco mais de um quilômetro, ocupando lados diferentes do Stanley Park. O bairro de Anfield fica vizinho ao bairro Everton, enquanto que o Everton FC, ao mudar-se para o outro lado do Stanley Park, acabou por fixar-se em Goodison Road, no bairro de Walton.

Os tijolos empregados na construção de ambos sugerem simultaneidade das obras, ainda que adotando estilos característicos e diversos; o estádio, construído em 1892 foi remodelado em 1909 pela orientação de Archibold Leitch (GIULIANOTTI,1999), arquiteto dos principais estádios da Grã-Bretanha, como o Highbury do Arsenal, The Old Trafford do Manchester United, e o Ibrox do Glasgow Rangers (FOUR FOUR TWO,2015). O mesmo Leitch retornaria em 1926 para ampliar o estádio, construindo o double deck da Goodison Road Stand, que seria reformado em 1971, transformando-se numa arquibancada de três andares. 
Celso Vieira Jr.

Goodison Park tem uma tradição pioneira no futebol inglês: foi o primeiro estádio a receber um monarca (o rei Jorge V, em 13 de julho de 1913, em evento beneficente), e por anos esteve na vanguarda tecnológica, usando sistemas de iluminação, irrigação, drenagem e derretimento da neve, incomuns desde os anos 1960. Tais características credenciaram o Goodison Park como um dos principais estádios da Grã-Bretanha, o levando inclusive a ser eleito uma das sedes da Copa do Mundo de 1966 disputada na Inglaterra, sendo o segundo estádio que mais recebeu partidas da competição, atrás apenas de Wembley, palco da final. E mesmo com as adaptações feitas ao estádio por exigência da FIFA (como uma distância maior entre torcida e linha de fundo), as imagens televisadas do torneio surpreendem pela presença massiva do público no estádio. A imagem nos traz uma sensação de claustrofobia e, a exemplo da fotografia aqui analisada, centenas de pessoas se espremem de pé num espaço exíguo. Aqui chegamos ao que poderia ser esboçado como um conflito entre estilos moderno e pós-moderno (HARVEY, 1992, p. 50). Leitch foi um construtor de fábricas antes de tornar-se o principal nome na arquitetura dos estádios britânicos. Logo, emprestou-lhes diversos traços aplicados nas fábricas construídas por ele na virada do século XIX para o XX: arquibancadas cobertas nas laterais e em um dos fundos, um setor descoberto onde os torcedores ficavam em pé, emprego de aço nas estruturas e fachadas externas enormes e maciças, feitas de tijolos, que combinavam prédios de escritórios (os estádios passaram a ser não apenas campos de futebol como também sedes sociais) com arquibancadas. A arquitetura do estádio de futebol tipicamente britânica, inventada por Leitch, tinha por característica comportar o maior número de pessoas possível nesse amplo espaço sob a menor intervenção.

Públicos massivos eram comuns desde o início do futebol britânico, e este espaço, embora amplo, tornava-se apertado pelo enorme número de pessoas. O público era confinado no interior dos estádios sem maiores preocupações com circulação, e isto nunca foi considerado um problema na Grã-Bretanha. Outrossim, os estádios foram desenhados para um público médio de vinte mil pessoas. No caso do Everton, o público médio após a Segunda Guerra Mundial atingiu quarenta mil pessoas, com partidas episódicas (jogos 
O sagrado, o profano e os seus diferentes tempos convergentes: uma fotografia "futebolística" de Peter Robinson (Liverpool, Inglaterra, 1971)

decisivos, fases eliminatórias de Copas, o Derby contra o Liverpool, etc.) recebendo até sessenta mil pessoas. Apenas durante a crise do futebol inglês dos anos 1980 (crise por sua vez inserida no complicado contexto social da Grã-Bretanha do final dos anos 1970, com quadro de recessão e desemprego), o Everton viu suas médias recuarem a menos de vinte mil pessoas. Tal arquitetura passou a ser a característica dos estádios britânicos: um grande prédio inserido num bairro populoso, base de sua torcida, por sua vez acanhado, apertado e sem impedimento de acesso ao gramado (ainda assim ninguém arriscava-se a invadir o terreno de jogo, uma característica social inglesa identificada por Elias e Freud como elemento do "processo civilizador" (FRANCO JR., 2002, p.25). Já no resto da Europa, por sua vez, temos os estádios de perfil olímpico, ou seja, com grandes distâncias entre o público e o gramado, pois separados ou por pistas de atletismo ou por fossos e alambrado. Tais estádios surgiram com o advento dos Jogos Olímpicos, em 1896, e passaram a ser adotados como modelos para o futebol também, permanecendo até hoje, embora não em caráter exclusivo. Ou seja, a imagem nos sugere impor estranhamento de uma arquitetura tipicamente britânica. No entanto, a configuração moderna dos estádios passou a sofrer golpes do pósmodernismo. No caso episódico do Everton, a revolução pós-moderna foi "desviada"; embora ocorresse dentro do espaço de tempo classificado como "pós-moderno" por Harvey, a obra pode ser considerada paliativa: a intervenção na Goodison Road Stand foi impressionante pelo tamanho atingido pela arquibancada principal, agora com três andares, porém não representou grande inovação. Deste modo, Goodison Park mostrou-se uma permanência moderna, ou seja, mantida sob os padrões modernistas (retas, espaço dirigido etc), como um resquício de um tempo que já se mostra passado.

No entanto, o caso do Everton não foi nada dramático como os de Ibrox em 1971, Heysel em 1985, e Hillsborough em 1989, todos eventos trágicos cuja a morte de torcedores deveu-se em grande medida à inépcia da polícia para lidar com grandes multidões (GIULIANOTTI,1999), boa parte da culpa foi atribuída às estruturas arquitetônicas, 
Celso Vieira Jr.

consideradas inadequadas para uma grande multidão ${ }^{4}$. A pós-modernidade sugeria uma alteração nos estádios britânicos, propondo novos modelos considerados mais seguros e confortáveis. Somente após a sequência das citadas tragédias, que resultaram em mortes envolvendo torcedores dentro de estádios, houve ações estatais visando a remodelação dos estádios. Aqui se faz necessário observar alguns aspectos do Reino Unido dos anos 1970 para compreender tanto a incidência das tragédias em um período curto de tempo, quanto as maneiras adotadas para solucionar o problema. Não por acaso, o pós-modernismo, como aponta Harvey (HARVEY, p. 44), está "em algum ponto entre 1968 e 1972", que também é momento de crise do pós-guerra, sentido no Reino Unido pelas frequentes greves, sendo a mais famosa o Piquete de Saltley, nas usinas de carvão próximas a Birmingham, bem como o recrudescimento do terrorismo anti-britânico pelo Exército Revolucionário Irlandês (IRA). A incapacidade do governo trabalhista em solucionar a crise, somada às crises do petróleo de 1973 e 1979, levou à troca de gabinete do governo, assumido por Margaret Thatcher no final dos anos 1970. De orientação liberal na economia e conservadora na política, Thatcher seguiu um modelo de privatizações de companhias públicas, controle e corte de gastos estatais e repressão, tanto local, com ações truculentas da polícia ao lidar com piquetes e greves, quanto internacional, vide a adoção da política de guerra contra a Argentina ao tratar das Malvinas. A tragédia de Hillsborough, quando 96 torcedores morreram esmagados ou asfixiados em 15 de abril de 1989, embora envolva a torcida do Liverpool, presente na tragédia de Heysel de 1985, em nada teve a ver como hooliganismo (GIULIANOTTI, 1999). A tragédia demonstrou que o futebol local na Grã-Bretanha havia atingido o seu ponto mais baixo em termos de descaso do poder público associado à incompetência da polícia em lidar com multidões em estádios velhos e decadentes. O Relatório Taylor, resultado do inquérito que apurou o desastre de Hillsborough, foi publicado em 1992 e recomendava a adoção de lugares sentados e marcados para todos os torcedores como forma de controlar o público

4 A tragédia de Heysel, na Bélgica, pela final do Campeonato Europeu de Clubes Campeões em 1985 envolvia um clube inglês, o Liverpool, porém as mortes ocorreram por uma combinação entre hooliganismo, incompetência e condição precária do estádio. Torcedores do Liverpool avançaram ao setor reservado aos torcedores da Juventus. Os torcedores viram-se encurralados e acabaram por espremerem-se contra o muro, que desabou, matando 39 pessoas. (O ESTADO DE SÃO PAULO,2015) 
O sagrado, o profano e os seus diferentes tempos convergentes: uma fotografia "futebolística" de Peter Robinson (Liverpool, Inglaterra, 1971)

que estava no interior do estádio. No mesmo ano, os principais clubes ingleses se uniram e romperam com a Federação Inglesa, passando a organizar o próprio campeonato, a Premier League, obtendo vultosos patrocínios financeiros. Isto levou a uma elitização sem precedentes no esporte. De mesmo modo, a remodelação dos estádios, que se por um lado visava expulsar um certo tipo de público, os hooligans, associados a vandalismo e violência, por outro permitiu ao futebol inglês se recuperar em termos de poder e prestígio (THE GUARDIAN, 2017). O corner end foi substituído por lugares marcados vendidos a preços muito mais elevados. Foi como se o modelo visto no canto superior direito da imagem replicasse por todo o estádio. Não há nada semelhante em termos de preço e acomodação no atual Goodison Park e outros estádios britânicos em comparação com o corner end, cujo desaparecimento, aliado à mudança no perfil do público que frequenta estádios ao longo dos últimos quase cinquenta anos. Sendo assim, esta imagem registrada em 1970 por Robinson é, para além de seus componentes estéticos, de representação e de função, um registro de uma realidade que não existe mais.

A ausência do corner end e a mudança de hábitos nos estádios pode conduzir a uma nostalgia de um tempo que, se não era necessariamente melhor do que o atual, carrega um significado algo romântico de um futebol realmente popular. Conforme Mircea Eliade, a nostalgia:

Conduz fatalmente à contínua repetição de um número ilimitado de gestos e comportamentos. De certo ponto de vista, pode-se dizer até que o homem religioso - sobretudo o das sociedades primitivas- é por excelência um homem paralisado pelo mito do eterno retorno. (ELIADE, 1992, p. 78)

\section{A igreja}

Em 1889, em Goodison Park, ergue-se em madeira a capela anglicana de St. Luke the Evangelist. Como dito anteriormente, a igreja foi reformada pelo arquiteto James Frances Doyle e previa um relógio e um pináculo em seu projeto, que acabaram não incluídos na obra. 
Celso Vieira Jr.

As igrejas foram muito importantes para o fomento do futebol no final do século XIX. Muitos clubes foram fundados com o apoio das paróquias locais. O San Lorenzo de Almagro, de Buenos Aires, foi um de muitos clubes que em seus primeiros dias se apoiaram nestas comunidades que se formavam em torno das igrejas (FABBRI, 2005, p. 73-74). Em Liverpool, operou-se da mesma forma e com um componente a mais: a cidade era um dos grandes pontos de atração da imigração irlandesa durante o século XIX, contando com a segunda maior comunidade irlandesa da Inglaterra depois de Londres. Eram 76 mil nativos da Irlanda em 1871, perfazendo 15\% da população da cidade (KENNEDY, 2017, p. 7), de forma que o conflito entre protestantes e católicos, presente em todo o Reino Unido, tomou contornos elevados na cidade (KENNEDY, 2017, p. 8). Liverpool, inclusive, está mais próxima de Dublin do que de Londres. O Everton foi fundado em 1878 com o nome de Saint Domingo em alusão à paróquia metodista homônima em torno da qual o clube se organizou; porém, após a cisão de 1892 que levou à fundação do Liverpool FC e a perda da sede de Anfield, o clube notabilizou-se por atrair a simpatia da parcela irlandesa da cidade, em sua maioria católica, ao passo que o rival passou a ser caracterizado como o bastião protestante. No entanto, ao contrário do que ocorre em Glasgow, Edimburgo, Belfast ou Dublin, as características da “Old Firm" (rivalidade religiosa institucionalizada) não se concretizaram em Liverpool, ainda que popularmente haja esta ideia, conforme relato da popular cantora dos anos 1960 e 1970 Cilla Black (liverpooliana e uma das primeiras artistas a assinar com o selo Apple dos Beatles): “Em Liverpool, muitos dos protestantes eram Conservadores e a maioria dos católicos eram Trabalhistas, assim como o Everton era associado como o time católico enquanto o Liverpool era considerado o protestante" ${ }^{\prime 5}$ (BLACK apud KENNEDY, 2017, p. 9).

Tommy Smith, um dos grandes nomes da história do Liverpool, jogador campeão diversas vezes pelo clube nos anos 1970, reforça o mesmo conceito, ao passo que sua declaração demonstra que há muito mais folclore do que sectarismo, de fato, na cidade de Liverpool:

5 No original: "In Liverpool, even in two-ups and two-downs most Protestants were Conservative and the most Catholic were Labour, just as Everton was the Catholic team and the Liverpool the Proddy-Dog one" 
O sagrado, o profano e os seus diferentes tempos convergentes: uma fotografia "futebolística" de Peter Robinson (Liverpool, Inglaterra, 1971)

Por tratar-se de um colégio vinculado à hierarquia da Igreja Católica Romana, a religião ocupava um importante papel na vida escolar. Padre Moran inclusive tentou me convencera a não ir para Anfield torcedores e jogadores católicos usualmente associavam-se ao Everton, ao passo que o Liverpool era o time protestante. O padre de fato imaginou que eu não poderia ser feliz em Anfield por ser católico. ${ }^{6}$ (SMITH apud KENNEDY, 2017, p. 9)

Ou seja, embora não haja fontes que comprovem a intenção de Robinson, a foto registra a igreja protestante ao lado do Goodison Park, relatando essa ambiguidade na proximidade e relação entre o clube "católico" com uma igreja protestante, ao contrário do que sugere o folclore liverpooliano. Kennedy, demonstra que a lógica associativa entre clube católico versus clube protestante existe, porém não apresenta em Liverpool o aspecto sectarista presente em Glasgow ou Belfast, de forma que sim, houve vínculos em seus inícios mas que foram superados pela popularização em massa do futebol na cidade (Kennedy,2017).

Por muitas vezes foi discutido o valor simbólico religioso atribuído ao futebol por seus seguidores, seja pela violência (hooliganismo, torcidas organizadas, etc) seja pela metáfora religiosa em si (FRANCO, 20078, p. 258). Ao enquadrar o público do esporte simultâneo à igreja num determinado espaço delimitado, temos a sugestão da alteração das afeições religiosas em determinado tempo registrado. A imagem nos traz a multidão como em comunhão. A forma de envolvimento com o esporte é maior passando pela experiência do jogo ao vivo no estádio, e a comunhão com os outros torcedores é parte da experiência que cria este impacto. O retorno ao estádio, a programação previsível e ordenada remete a uma replicação do tempo, uma repetição que remete ao ritual. Os jogos repetem-se, têm sempre o mesmo tempo aproximado, com enredos diferentes porém sempre num espectro aguardado. O esporte alterou-se desde seu surgimento até o instantâneo registrado; porém algumas situações são basilares e se repetem: haverá sempre uma assistência, uma equipe adversária, um objetivo a alcançar dentro de 90 minutos (ou pouco mais). Talvez a dinâmica do jogo se dê

6 No original: “Being a Catholic Roman School, religion played a large part in our school life. Pop Moran even tried to turn me off football at Anfield - Catholic were traditionally Everton supporters and players; Liverpool were the Protestant team. Pop honestly thought that being a Catholic I wouldn't be happy at Anfield". 
Celso Vieira Jr.

de maneira muito diversa ao longo do tempo, porém a base mantém-se identificável. Sobre a comunhão entre o sagrado e o tempo, Eliade (1998, p. 59-60) afirma: “Participar religiosamente de uma festa implica a saída da duração temporal 'ordinária' e a reintegração no Tempo mítico reatualizado pela própria festa".

Obviamente Eliade está referindo-se a rituais religiosos instalados e consagrados; porém, classificando profanamente a comunhão da plateia futebolística como um ritual, como a imagem sugere, a citação vale destacar as palavras de Franco:

"O futebol é meio de reprodução simbólica do corpo social, da mesma maneira que a guerra nas sociedades tradicionais, nas quais ela está codificada de maneira estrita, visando não perturbar a vida dos grupos envolvidos. Daí haver um calendário para a luta, cujas retomadas periódicas ganham feições lúdicas" (FRANCO JR, 2007, p.201-202).

E os tempos do esporte, especificamente do futebol profissional, conferem. Há as temporadas que regularmente repetem-se em um calendário previsto. Os desfechos dos torneios alteram-se dentro de um tempo estabelecido, da mesma forma que o clima é previsto, porém não exato, repetindo-se dentro dos ciclos das estações conhecido. Há a estação chuvosa, embora não saibamos o quanto irá chover. Há o período de seca cuja extensão temporal pode ser ideal ou desastrosa.

\section{A multidão}

Estamos na virada dos anos 1960 para os 1970, e novamente Harvey (1992, p. 45) aponta-nos que é o momento em que surge o pós-modernismo, como o estilo das pessoas jovens sugere-nos: cabelos longos, barbas e bigodes característicos da época. Interessante notar que o pós-modernismo se revela de modo mais fácil no estilo de roupas, barba e cabelo que, quando colocados em conjunto com a igreja e estádio, reforçando o contraste entre moderno e pós-moderno. As construções demandam grandes movimentos e esforços combinados para realizar uma mudança. O Everton somente agora, no século XXI, prevê uma mudança para um novo estádio a ser construído sobre as normas exigidas atualmente (EVERTON FC,2018). Voltando à fotografia de Robinson, o instantâneo retrata também a atenção da multidão. Com exceção das crianças em primeiro plano, a maioria das pessoas expressa atenção, foco e certa apreensão. Retoma-se aqui uma falsa oposição: a de uma 
O sagrado, o profano e os seus diferentes tempos convergentes: uma fotografia "futebolística" de Peter Robinson (Liverpool, Inglaterra, 1971)

multidão com expressão adequada a um serviço religioso. A fotografia, porém, apresenta, além de uma assistência reduzida, expressões desatentas e muitas vezes sonolentas. A imagem traz esta oposição entre o que era esperado para a igreja em outro espaço e momento e onde de fato o comportamento da massa ocorre. Embora possa haver nesta multidão uma intersecção entre torcedores de futebol e homens religiosos que tenham frequentado o serviço religioso pela manhã, Mircea Eliade oferece um olhar que nos parece adequado também a esta massa:

Ora, o que se pode constatar relativamente a um homem não-religioso é que
também ele conhece uma certa descontinuidade e heterogeneidade do
Tempo. Também para ele existe o tempo do lazer e dos espetáculos, numa
palavra o "tempo festivo". Também ele vive em ritmos temporais variados e
conhece tempos diferentemente intensos: [...] ele experimenta,
evidentemente, um ritmo temporal diferente de quando trabalha ou se
entedia. (ELIADE, 1992, p. 78)

A fotografia de Robinson nos mostra uma plateia que está experimentando, em conjunto, um tempo parcialmente distinto daquele que o relógio sugere. O jogo havia começado há pouco mais de cinco minutos. As crianças ainda se mostram alegres e empolgadas ao passo que os adultos já se contraem em ansiedade, tensão e nervosismo. Muitos já acenderam, após o início da partida, um cigarro, e muitos outros se seguirão no decorrer do jogo.

Não só um dos tempos experimentados pelos espectadores pode ser muito maior do que os poucos seis minutos do relógio apontam, como também pode ser vivido de forma diferente entre as faixas etárias presentes no terrace. A capacidade e compleição física denotam também diferentes formas como o tempo é sentido. Adultos jovens resistem de determinada forma à condição em ficar de pé durante o tempo de jogo. Crianças e idosos tendem a cansar e procurar apoio. Considerando que uma ida ao estádio implica em pelo menos uma hora e meia em pé no estádio, as formas como se sente o tempo pelas diferentes pessoas, no mesmo lugar, também varia. 
Celso Vieira Jr.

“Lembro-me da esmagadora masculinidade daquilo tudo - a fumaça de charuto e cachimbo, o linguajar obsceno (palavras que eu já ouvira antes, mas não ditas por adultos e naquele volume)" (HORNBY, 2000, p.19). Esta passagem do livro de Hornby ilustra um outro componente da imagem a ser destacado: a quase completa ausência de mulheres. As duas únicas figuras a quem poderíamos atribuir o gênero feminino não aparentam estar presentes por interesse na partida, e sim por algum motivo paralelo. A provável mulher à esquerda, que se segura junto à grade azul, não olha para o campo, e sim dirige-se a alguém que provavelmente lhe faz companhia. Talvez um filho ou parceiro que seja um genuíno fã e que a compeliu a acompanhá-lo. A segunda pode ser uma garota de aspecto algo andrógino sentada no canto inferior esquerdo, vestindo uniforme entre os colegas, e cuja única diferença reside nos sapatos e nas meias. E assim como a assinalada anteriormente, olha para outro lado que não o campo. A audiência é massivamente masculina, e a relativa familiaridade e proximidade temporal que ainda temos com a época registrada na imagem de certa forma contamina nossa percepção do quão masculino era (e ainda é sob certos aspectos) o estádio de futebol. Fora do estádio, masculino, temos a igreja, de costas, mais uma vez em oposição e, por sugestão de frequência majoritariamente feminina.

Por fim, temos os garotos situados em primeiro plano na arquibancada. As crianças posicionam-se nas primeiras fileiras não só por conta de sua menor estatura como também pela possibilidade de assim descansarem o peso do corpo sobre as pernas, apoiando-se na mureta que divide o público do gramado. Eles estão especialmente próximos a Robinson, e não só compõem a imagem como nela interferem por conta da consciência de estarem sendo fotografados. Eles encaram a câmera e fazem gracejos, quebrando o aspecto contemplativo que a imagem traz, porém, sem anulá-lo. Esta intervenção dos garotos traz outro componente da construção da imagem, uma certa consciência de que a realidade são eles, os garotos que assistem a uma partida numa tarde sábado enquanto a foto será apenas uma representação do que foi aquele momento, em seus muitos aspectos, em seus vários tempos. 
O sagrado, o profano e os seus diferentes tempos convergentes: uma fotografia "futebolística" de Peter Robinson (Liverpool, Inglaterra, 1971)

\section{Conclusão}

A imagem existe e tem valor como documento e registro; porém, como o garoto jocoso que mostra a língua sugere dizer, "não sou assim: só faço isso quando vejo uma câmera". Esta provocação lembra-nos que a imagem é apenas um indício da realidade, portadora de intenções, possibilidades e representações, jamais sendo abarcada de forma "completa", como aponta Aumont. Mesmo assim, ainda que o instante fugidio que lhe dá razão de ser imediata não seja capaz de abarcar a totalidade de seus significados, podemos utilizá-la não só como um documento, mas como um suporte de legitimidade confrontado com outros artefatos, portadores inclusive de outros tempos.

A imagem em si pode não oferecer explicação de nada; mas sabendo interpelá-la, ela se revela rica fonte para o entendimento da sociedade que a produziu, e das sociedades que a consumiram. No mais, a imagem também apresenta o caráter acumulador, "empilhador" de tempos diferentes e articulados nela presentes, por ela materializados. Antes, durante, depois; passados, presentes e futuros.

\section{Referências bibliográficas:}

AUMONT, Jacques. O olho interminável: cinema e pintura. São Paulo: Cosac Naify, 2004.

BEAZLEY, Mitchell. Football days: classic football photographs by Peter Robinson. Londres: Octopus, 2003.

CIPOLLA, Carlo. Las maquinas del tempo. México: FCE, 1998.

EFC HERITAGE SOCIETY. Disponível em < http://efcheritagesociety.com/?p=1313>. Acesso em 12.mar.2018

ELIADE, Mircea. O Sagrado e o profano: essência das religiões. São Paulo: Martins Fontes, 1992.

EVERTON FC. History Of Goodison Park. Disponível em: <http://www.evertonfc.com/content/his tory/history-of-goodison-park>. Acesso em: 24.fev.2018.

. Our Former Homes. Disponível em: < http://www.evertonfc.com/content/history/historyof-goodison-park/the-grounds-of-everton>. Acesso em: 24.fev.2018.

. NEW STADIUM key principles. Disponível em <http://www.evertonfc.com/functional/yourstadium/key-principles>. Acesso em 12.mar.2018. 
Celso Vieira Jr.

EVERTON RESULTS. Disponível em < https://www.evertonresults.com/>. Acesso em 12.mar.2018.

EVERTON OBEY holy orders. BBC News. Disponível em: <http://news.bbc.co.uk/sport2/hi/fun ny old game/1791575.stm>. Acesso em: 24.fev.2018.

FABBRI, Alejandro. El nacimiento de uma pasión. Buenos Aires: Capital Intelectual, 2006.

FRANCO JR., Hilário. A Dança dos deuses. Futebol, Sociedade, Cultura. São Paulo: Companhia das Letras, 2007.

FOUR FOUR TWO. MEET ARCHIBALD LEITCH. Disponível em < https://www.fourfourtwo.com/ features/meet-archibald-leitch-man-who-invented-football-stadium>. Acesso em 12. mar. 2018.

GIULIANOTTI, Richard. Sociologia do Futebol. Dimensões históricas e socioculturais do esporte das multidões. São Paulo: Nova Alexandria, 1999.

HARVEY, David. Condição pós-moderna. São Paulo: Loyola, 1992.

HORNBY, Nick. Febre de bola. Rio de Janeiro: Rocco, 2000.

KENNEDY, David. Merseyside's Old Firm? The Sectarian Roots of Everton and Liverpool Football Clubs. Liverpool: Amazon Books, 2017.

; KENNEDY, Peter. Irish Football Clubs in Liverpool. Liverpool: Amazon Books, 2017

KOSELLECK, Reinhart. Futuro passado: contribuição à semântica dos tempos históricos. Rio de Janeiro: Contraponto, 2006.

LE GOFF, Jacques. História e Memória. Campinas: Unicamp, 2012.

Para um novo conceito de Idade Média: tempo, trabalho e cultura no Ocidente. Lisboa: Estampa, 1979.

LIVERPOOL ECHO. Prentice: Times past but Littlewoods clocks are precious artefacts still. Disponível em < https://www.liverpoolecho.co.uk/sport/football/football-news/prentice-timespast-littlewoods-clocks-10080068>. Acesso em 12.mar.2018.

LIVERPOOL FC. THE HISTORY OF Liverpool. Disponível em: < http://www.liverpoolfc.com/history $>$. Acesso em 12.mar. 2018.

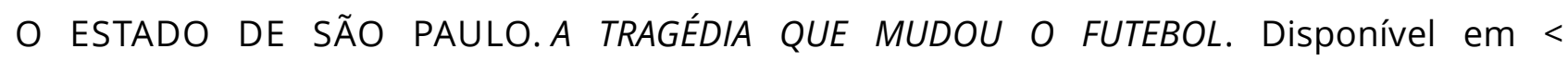
http://infograficos.estadao.com.br/esportes/tragedia-futebol-30-anos-heysel/>. Acesso em 12.mar.2018.

PRADO, Décio de Almeida. Tempo (e espaço) no futebol. Revista USP 2, junho/julho/agosto 1989, p.15-24

SÔNEGO, Márcio Jesus Ferreira. A fotografia como fonte histórica. Historiæ. Rio Grande, v. 1, n.2, 2010. 


\section{dossiê}

O sagrado, o profano e os seus diferentes tempos convergentes: uma fotografia "futebolística" de Peter Robinson (Liverpool, Inglaterra, 1971)

TOFFEE ART. Disponível em < http://www.toffeeart.co.uk/product/goodison-desktop-clock/>. Acesso em 12.mar.2018.

THOMPSON, Edward. Costumes em comum. São Paulo: Companhia das Letras, 1998.

THE GUARDIAN.20 January 1974: The first Sunday football. Disponível em: <https://www.thegu ardian.com/sport/2010/jan/23/first-sunday-football-1974-millwall-fulham>. Acesso em 12. mar. 2018

.DECEIT, DETERMINATION AND MILLIONS. Disponível em : < https://www.theg uardian.com/football/2017/jul/23/deceit-determination-murdochs-millionshowpremierleaguewas-born>. Acesso em 12.mar.2018.

\section{Imagens}

Imagem 1: PA Images. A view of the Church of St Luke the Evangelist, which sits in the corner of Goodison Park. 1971. 